\title{
Assessment of Fatal Firearm Injuries in Cairo and Giza Governorate: Analytical Study (2014)
}

\author{
Magdy A. Ismail ${ }^{1}{ }^{1 *}$ MD., Sherif F. Mahmoud ${ }^{1}$ MD., and Omar M. Sayed ${ }^{1}$ MB BCh.
}

\author{
* Corresponding Author: \\ Magdy A. Ismail \\ amagdy153@yahoo.com
}

Received for publication February 18,2020; Accepted

March 16, 2020; Published

online March 18, 2020

Copyright 2020 The Authors published by Al-Azhar University, Faculty of Medicine, Cairo, Egypt. All rights reserved. This an openaccess article distributed under the legal terms, where it is permissible to download and share the work provided it is properly cited. The work cannot be changed in any way or used commercially.

doi: $10.21608 /$ aimj.2020.24195.1147

\author{
ABSTRACT \\ Introduction: Every year hundreds of thousands of people die from \\ injuries caused by firearms. Therefore, the present work aimed to \\ determine and analyze the pattern of firearm injuries among deaths on \\ which medicolegal autopsies were conducted at Cairo Department of \\ Forensic Medicine (Zeinhom mortuary), Ministry of Justice, Egypt, \\ during 2014 .
}

Material and Methods: Dat a were obtained from available medicolegal reports and were statistically analyzed.

Results: There were 468 firearm deaths representing $26.3 \%$ of the total deaths received during the study period.

Conclusion: Most of cases were males in the age group (20-30) years. In most of the cases $(93.4 \%)$ there is no relation between assailant and victim. There was a high prevalence $(68.6 \%)$ of rifled weapons and chest was the most common injured anatomical region (38.2\%), followed by head $(36.9 \%)$. Homicidal manner was the most common (91.7\%) and the majority $(88.5 \%)$ of cases died suddenly without any medical intervention. The major mechanism of death was hemorrhagic shock $(60.5 \%)$.

Keywords: Fatal injuries; firearms; Cairo; Giza; Analytical study.

Forensic medicine \& clinical toxicology Department, Faculty of Medicine, Al-Azhar University Cairo, Egypt.

Disclosure: The authors have no financial interest to declare in relation to the content of this article. The Article Processing Charge was paid for by the authors.

Authorship: All authors have a substantial contribution to the article.

\section{INTRODUCTION}

Firearm injuries are a significant cause of morbidity and mortality, with a higher prevalence both in developing and developed countries depending on the gun's access, law, and regulations as well as cultural specifics, firearms in peace time and non military conflict areas cause about 1.2 million deaths and injure more than 10 million people annually worldwide. ${ }^{1}$

A huge emotional, physical and financial burden is borne by the patient of firearm injury, affecting his family and society. This is as a result of the unpredictability of gunshot injuries with potentials for causing damages through wide mechanisms. ${ }^{2}$ the severity of firearm injury depends on the type of firearm and the distance between the firearm and the body part, which is shot.

After the revolution of 2011, an expansion in the rate of violence was noted in Egypt. ${ }^{4}$ In Egypt, only few studies were conducted to describe the pattern of firearm injuries, therefore, the present work aimed to determine and analyze the pattern of fatal firearm injuries among deaths on which medicolegal autopsies were conducted at Cairo Department of

Forensic Medicine (Zeinhom mortuary), Ministry of Justice, Egypt, during 2014

\section{MATERIAL AND METHODS}

This is a retrospective analytical study that was carried out on all cases of fatal firearm injuries on which medicolegal autopsies were conducted at Cairo Department of Forensic Medicine (Zeinhom mortuary), Ministry of Justice, Egypt, during 2014.

Data of this study were collected from the autopsy reports that list fatal firearm injuries as a cause of death after consent was obtained from Zeinhom mortuary. The study was approved by The Local Ethical Committee of the Faculty of Medicine, AlAzhar University, Egypt. The studied cases were assessed regarding the incidence rate of deaths due to fatal firearm injuries in relation to the total deaths received during the studied period, Demographic data: victim's age, gender, area distribution [ Cairo and Giza ((modern and rural areas)) ] and relation between assailant and victim and Autopsy and 
medico-legal data: time passed from injury to death, manner of death, type of firearm, anatomical site of fatal injury, presence of surgical or medical interference, number of inlets and exits, presence of retained bullet, presence of weapon and mechanism of death.The collected data were tabulated and statistically analyzed using SPSs version 16 microstate software package (SPSs Inc, Chicago, ILL Company).

The significance of difference was tested using: $\mathrm{Z}$ test, chi square test (X2-value) and fisher exact test (FET). A P- value of $<0.05$ was considered statistically significant $(\mathrm{S})$ while $>0.05$ statistically insignificant and a $\mathrm{P}$ value $<0.01$ was considered highly significant (HS)

\section{Results}

The study include all cases with firearm injuries in Cairo and Giza Governorates during the period of one year as a retrospective study during 2014 .

The present study reported a total of 468 deaths due to fatal firearm injuries representing $26.3 \%$ of the total number (1778) of unnatural deaths that had been received during the studied period.

Regarding the prevalence of firearm deaths in different areas of Cairo and Giza governorates,297 cases $(63.5 \%)$ came from urban areas (Cairo), while 171 cases $(36.5 \%)$ came from rural areas (Giza); the largest prevalence was found in East Cairo $(47.1 \%)$ while the least number was in Middle Cairo (10.8\%).

The present work showed that the highest frequency of injuries was among those in the 3rd decade which accounted for $(45.5 \%)$, while the lowest was among those in the 1 st decade $(2.3 \%)$. The majority of cases were males 444 cases, while females constituted only 24 cases of the total cases. As shown in table (1) and Fig. (1).

\begin{tabular}{|c|c|c|c|c|c|c|c|c|c|}
\hline \multicolumn{2}{|c|}{ Age } & $\begin{array}{c}\text { 1st } \\
\text { decade }\end{array}$ & $\begin{array}{c}\text { 2nd } \\
\text { decade }\end{array}$ & $\begin{array}{c}\text { 3rd } \\
\text { Decade }\end{array}$ & $\begin{array}{c}\text { 4th } \\
\text { decade }\end{array}$ & $\begin{array}{c}\text { 5th } \\
\text { decade }\end{array}$ & $\begin{array}{c}\text { 6th } \\
\text { Decade }\end{array}$ & $\begin{array}{c}\text { 7th } \\
\text { decade }\end{array}$ & Total \\
\hline \multicolumn{2}{|c|}{ Cairo } & 6 & 26 & 144 & 71 & 28 & 16 & 6 & 297 \\
\hline \multicolumn{2}{|c|}{ Giza } & 5 & 11 & 69 & 50 & 19 & 11 & 6 & 171 \\
\hline \multirow{2}{*}{ Total } & $\mathbf{N}$ & 11 & 37 & 213 & 121 & 47 & 27 & 12 & 468 \\
\hline & $\%$ & 2.3 & 7.9 & 45.5 & 25.8 & 10.1 & 5.8 & 2.6 & $\overline{100.0}$ \\
\hline
\end{tabular}

Table 1: Distribution of fatal firearm injuries according to age during year 2014

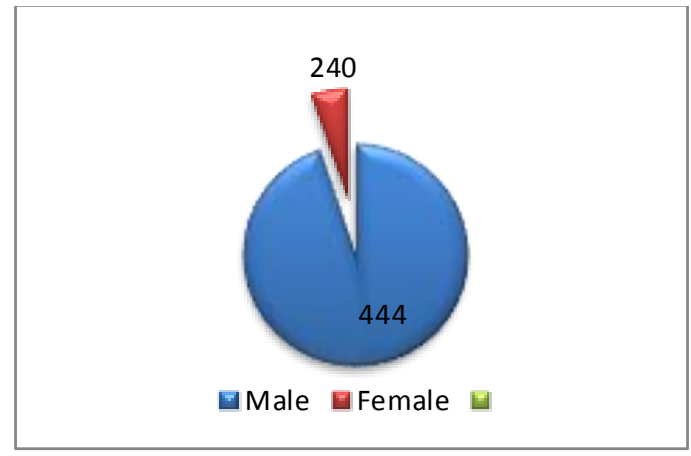

Fig. 1: Pie chart showing the distribution of studied cases $(n=468)$ according to gender during year 2014 .

In the present work there was no relation in $93.4 \%$ of cases while there was a relation in $6.6 \%$ of cases and there is no significant difference between Cairo and Giza Governorates.

The present study showed that the commonest site of injury was the chest $(38.2 \%)$, this was followed by head $(36.9 \%)$, abdomen injuries constituted (16.4\%), then neck injuries (8.5\%), then limbs injuries $(6.8 \%)$, the least anatomical site injured was the back $(4.7 \%)$. Combined sites were encountered (11.7\%).
The present study found that the manner of injury was homicidal in $(91.7 \%)$ of the cases, accidental in $5.5 \%$ of the cases and suicidal in $2.8 \%$ of the cases. As shown in Fig (2).

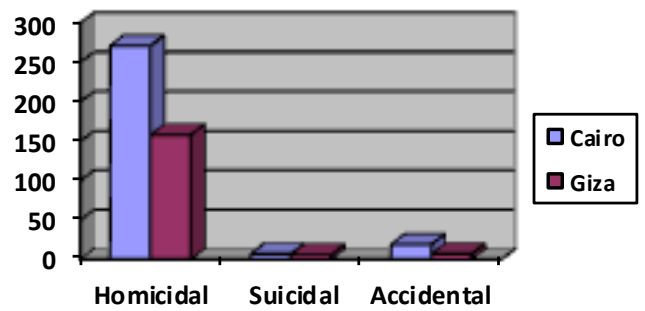

Fig. 2: Bar chart showing the distribution of studied cases $(n=468)$ according to manner of death during year 2014 .

The present study confirmed that 414 cases died suddenly without any medical intervention while 54 cases had received medical intervention, 42 cases lived form hours to few days, 12 cases lived from one week to about a month, As shown in table (2). 


\begin{tabular}{|c|c|c|c|c|c|}
\hline \multicolumn{2}{|c|}{$\begin{array}{c}\text { Time passed from } \\
\text { injury to death }\end{array}$} & Suddenly & $\begin{array}{c}\text { Early(hours } \\
\text { to few days) }\end{array}$ & $\begin{array}{c}\text { Late(week } \\
\text { to month) }\end{array}$ & Total \\
\hline \multicolumn{2}{|c|}{ Cairo GO V. } & 256 & 33 & 8 & 297 \\
\hline \multicolumn{2}{|c|}{ Giza GOV. } & 158 & 9 & 4 & 171 \\
\hline \multirow{2}{*}{ Total } & $\mathrm{N}$ & 414 & 42 & 12 & 468 \\
\cline { 2 - 6 } & $\%$ & 88.5 & 9.0 & 2.5 & 100.0 \\
\hline
\end{tabular}

Table 2: Distribution of fatal firearm injuries according to time between injury and death during the period of study.

Regarding residence of the victim, there were 171 cases out 468 cases $(36.5 \%)$ live in rural areas while 297 cases $(63.5 \%)$ live in urban areas. The most common cases occurred in summer (192 cases; $41 \%$ ) followed by winter (128 cases; $27.4 \%$ ) then spring (98 cases; $20.9 \%$ ) and finally in autumn (50 cases: $10.7 \%$ ) and there was statistically non significant difference between residence of the cases, in relation to the season of occurrence.

The present study proved that the far firing was the most common $(92.5 \%)$ among the studied group while the near firing is less common $(7.5 \%)$. Regarding the presence of retained missiles in the majority (51.7\%) of cases, there are retained missiles, as shown in fig (3).

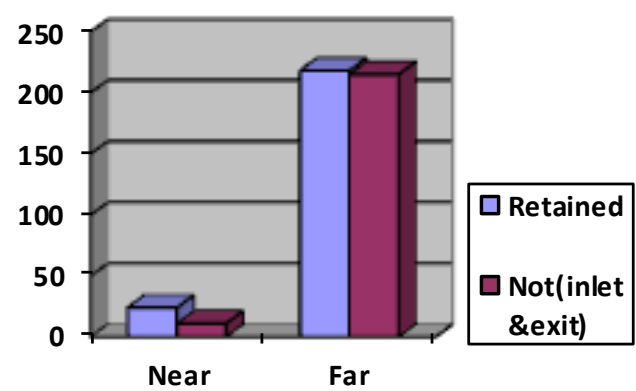

Fig. 3: Bar chart showing the distribution of studied cases ( $n=468)$ according to the presence of retained bullets and distance of firing during year 2014 .

The present study showed that rifled weapons were the most common as it were used in 321 cases $(68.6 \%)$, while Non- rifled weapons were less common as they used in 147 cases $(31.4 \%)$, as shown in Fig (4 ).

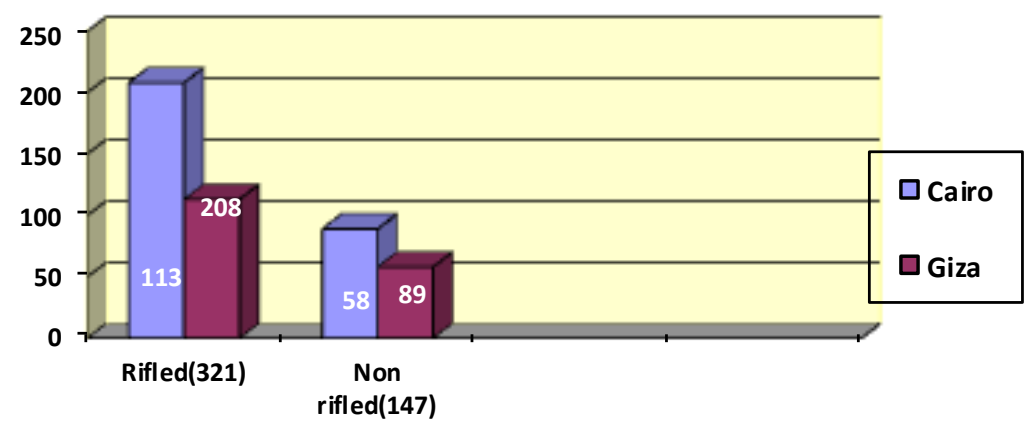

Fig. 4 : Bar chart showing the distribution of studied cases $(n=468)$ according to the Type of weapon in Cairo and Giza Governorates during year 2014.

The present study showed that the retained bullets were present in $51.7 \%$ of cases while absent in $48.3 \%$ of cases. Pellets were the most common as it were used in 117 cases $(48.3 .8 \%)$ followed by $9 \mathrm{~mm}$ (16.5\%) then 7.62 found in 35 cases (14.5\%) while large pellets were less common as they found in only 7 cases $(2.9 \%)$.
Regarding the mechanism of death; the commonest cause of death was the hemorrhagic shock $(60.5 \%)$, followed by brain hemorrhage and skull fracture $(36.9 \%)$ and lastly septic shock constituted $(2.6 \%)$ as shown in Table (3). 


\begin{tabular}{|c|c|c|}
\hline $\begin{array}{c}\text { Mechanism of } \\
\text { death }\end{array}$ & $\mathrm{N}$ & $\%$ \\
\hline $\begin{array}{c}\text { Hemorrhagic } \\
\text { shock }\end{array}$ & 283 & 60.5 \\
\hline $\begin{array}{c}\text { Brain } \\
\text { hemorrhage- } \\
\text { skull fracture }\end{array}$ & 173 & 36.9 \\
\hline Septic shock & 12 & 2.6 \\
\hline Total & 468 & 100.0 \\
\hline
\end{tabular}

Table 3: Distribution of fatal firearm injuries according to the mechanism of death during the year of 2014 .

\section{DISCUSSION}

The present study reported 468 cases of fatal firearm injuries representing $26.3 \%$ of the total number of cases (1778) received at Cairo Department of Forensic Medicine (Zeinhom mortuary), Ministry of Justice, Egypt, during 2014. representing about 2.9 deaths per 100,000 population.

According to Gramlich J. ${ }^{5}$ firearm deaths rate per 100.000 population in 2016 was (10.6) in U.S. , (2.1) in Canada, (1.0) in Australia, (2.7) in France, (0.9) in Germany, (0.6) in Spain, (39.2) in Salvador, (38.7) in Venezuela, and (25.9) in Colombia.

In the United States, 39,773 cases reported to have died due to firearm injuries, During the one-year period (2017), representing $0.16 \%$ of the total injury deaths, About 12.2 deaths per 100,000 population. ${ }^{6}$ Firearm crimes in this study are more in urban sites $(63.46 \%)$ versus rural $(36.54 \%)$. This was in agreement with Bradley et al. ${ }^{7}$ and disagreement with Gamal Eldin A. et al. ${ }^{8}$ who reported that firearm injuries were more common in rural areas.

In our study gunshot injuries more in urban than rural areas may be due to overcrowding of Cairo Governorate and occurrence of certain political events especially in East Cairo during 2014.

In the present work, it was found that male victims represented the majority $(94.9 \%)$ of the cases while females represented only $(5.1 \%)$. with male: female ratio of 18.6: 1. The most common affected age group in studied victims was the age group of the $3 \mathrm{rd}$ decade which accounted for ( $45.5 \%)$, while the lowest was among those in the 1 st decade $(2.3 \%)$.

This was in agreement with Jorgenson et al. ${ }^{y}$ in Oklahoma, who found that the most common cases is males (95\%) between the ages of 20 and 39 (64\%), Singh et al. ${ }^{10}$ in Uttar, who reported Males $(83.7 \%)$.

The results of the current study differ from that, of a study done by Cingöz ${ }^{11}$ in Aydin which showed that the age group of 31-40 was the highest with the rate of $(30.1 \%)$. For interpretation of these results, it can be said that elderly people tend to be wiser (wisdom increases with age) and act with restraint.

As regarding the manner of death, homicidal manner was the most common (91.7\%) followed by accidental (5.5\%) then suicidal manner (2.8\%). This was in accordance with Mary M. ${ }^{12}$ and Adawiyah et al. ${ }^{13}$ Who reported that homicide was the highest manner of death as compared to accidental and suicidal death.

This is quite different to Junuzovic et al. ${ }^{14}$, Katherine et al. ${ }^{15}$ and (CDPHE) ${ }^{16}$ they reported that suicides were the predominant group and homicides accounted for a small group of cases.

The present study revealed that, in $93.4 \%$ of cases there was no relationship between assailant and victim while there was a relation in $6.6 \%$ of cases. This was in agreement with Khan et al. ${ }^{17}$ and disagree with Shiffler et al. ${ }^{18}$

In the present study, chest was the most common $(38.2 \%)$ injured anatomical region, this was followed by head $(36.9 \%)$, abdomen injuries $(16.4 \%)$, then neck injuries $(8.5 \%)$, then the limbs injuries $(6.8 \%)$, and the least anatomical site injured was the back $(4.7 \%)$. This was in agreement with Umaz et al. ${ }^{19}$ and Saleh S.M. ${ }^{20}$ who reported that the chest and the abdomen were the most common sites of entrance wounds. On the other hand, Haider et al. ${ }^{21}$ found that The most common site of injuries were head, neck and face $(36.62 \%)$ of cases, while the least were the limbs $(4.22 \%)$. and Shah M.M ${ }^{22}$ confirmed that the most common anatomical site of fatal firearm injuries was the abdomen. Onuminya and Ohwowhiagbese ${ }^{23}$ found that extremities were the most common site affected. The high incidence of chest and head injuries in the present study may be due to the thinking as they contain vital organs. ${ }^{24}$

As regarding the distance of firing, the present study revealed that the majority $(92.5 \%)$ of cases were far firing while $(7.5 \%)$ were near firing. This was in accordance with Korai et al. ${ }^{25}$ and Al Madni O. ${ }^{26}$

On the other hand Kumar A. ${ }^{27}$ confirmed that close range fire was seen in maximum cases.

This study revealed that, rifled weapons were used in $68.6 \%$ of cases while non rifled weapons were used in $31.4 \%$ of cases. This in accordance with Lasebikan et al. ${ }^{28}$, Sultana et al. ${ }^{29}$ and Edirisinghe P.A. ${ }^{30}$

On the other hand Melissa et al. ${ }^{31}$ reported that locally made shotguns were responsible for maximum causalities.

This may be due to that many of the police centers were attacked during the peak days of revolution and also most of the weapons were stolen from these police centers by desperadoes. Furthermore, the Libyan Crisis opened another way for weapons to enter Egypt. ${ }^{32}$

As regarding medical intervention, this study showed that $(88.5 \%)$ died instantaneously, $(9 \%)$ died during 24 hours, $(2.5 \%)$ cases died between 2 days to 1 month, and only three could survive for more than one month. Which agree with Sachan et al. ${ }^{33}$ and Fedakar et al. ${ }^{34}$ While disagree with Hagras and Kharoshah ${ }^{35}$

As regarding cause of death, this study showed that, $(60.5 \%)$ died due to hemorrhagic shock, (36.9\%) died due to coma and brain injury, $(2.6 \%)$ died due to 
septic shock. This was in agreement with Umaz et al. ${ }^{19}$ and Sachan et al. ${ }^{33}$

\section{CONCLUSION}

Fatal cases due to firearm injuries constituted $26.3 \%$ of the total number of deaths that had been received during the period of the study, Deaths were more common among urban areas, and the third and fourth decades are the most affected age groups. There was no relation between assailant and victim in $93.4 \%$ of cases. Distant firing was more common than near firing. Suicides comprise a small number of included cases $(2.8 \%)$ in comparison to both homicides (91.7\%) and accidents (5.5\%) as firearms are less known as a mean of suicide in Egypt. Chest and head were the most common vulnerable sites for injuries $(38.2 \%)$ and $(36.9 \%)$ respectively. (88.5\%) of cases died immediately after injury and $11.5 \%$ were hospitalized for variable periods. The most common cause of death was either hemorrhagic shock or brain injury. The study revealed that rifled weapons were the most prevalent weapons $68.6 \%$ this may be due to many of the police centers were attacked during the peak days of revolution and also most of the weapons were stolen from these police centers by desperadoes. Furthermore, the Libyan Crisis opened another way for weapons to enter Egypt.

\section{ACKNO W LEDGMENT}

Our deep gratitude and thanks to all staff members in Cairo Department of Forensic Medicine (Zeinhom mortuary), Ministry of Justice, Egypt, for their great help and cooperation in collection of data for this study. Lastly we would like to extend our thanks to all of the staff members in Forensic Medicine and Clinical Toxicology Department, Faculty of Medicine, Al-Azhar University for their help and cooperation.

\section{REFER ENCES}

1. Morgan A, AlAqi N, AlGhaleb $\mathrm{S}$, et al. (2019): Firearm injuries in rural Saudi Arabia: incidence, patterns, management, and cost, Egyptian Journal of Forensic Sciences, January 05 .

2. Khan I, Shakeel M, Usmani JA, et al. (2016): Emerging Trends of Intentional Firearm Injuries in Northern India. A Study. J Clin. Diagn Res. Oct;10(10).

3. Orhan M, Caner S, Birdal G, et al. (2020): Investigation of firearm injury cases presented to training and research hospital's emergency service. Ulus Travma Acil Cerrahi Derg, 26(1): 74-79.

4. Enas M, Morsi M, and Amro S. (2019): Ain Shams Journal of Forensic Medicine and Clinical Toxicology 33 (2), 1-7.

5. Gramlich J. (2019): What data says about gun deaths in the u.s , Pew Research Center, August 16.

6. Kenneth D, Kochanek A, Sherry L, et al. (2019): National Vital Statistics Reports,vol. 68, No. 9: p12 June 24.
7. Bradley H, Julie G, James D, et al. (2018): Hospitalization for Firearm Injuries in children and Adolescent in US: Rural versus Urban, Pediatrics May, 142(1 Meeting Abstract) 721

8. Gamal Eldin A, El-Ghamry H, Ghaleb S, et al. (2008): Study of cases of firearms fatalities in El-Fayoum Governorate during 7 years period (2000-2006) retrospective study. Beni Sueif Univ Med J;1(1):70-92.

9. Jorgenson KM, Wiens AL, Pfeifer EA, et al. (2017):Trends in Officerinvolved Firearm Deaths in Oklahoma from 2000 to 2015. J Forensic Sci. Apr 4.

10. Singh SP, Prakash M, Chaudhary G, et al. (2017): Pattern of firearm injuries managed at rural tertiary centre in Western Uttar Pradesh, North India Int Surg J. Aug;4(8).

11. Cingöz G, Erel O, Dirlik M, et al. (2010): Deaths due to Gunshot Wounds in City of Aydin. The Bulletin of Legal Medicine; [S.1.], v. 15, n. 3, p. 84-90.

12. Mary Matecki. (2019): Cause of Death and Wound pattern in Firearm- Related Violence in Washinton, D.C. 5-1.

13. Adawiyah R, Hamzah NH, Hamzah AP, et al. (2018): Incidence of firearm-related deaths and epidemology in Klang valley, Malaysia from 2006 to 2016: A retrospective study. Malaysian Journal of Public Health Medicine; (1): 51-61.

14. Junuzovic M, Rietz A, Jakobsson U, et al. (2019): Firearm deaths in Sweden. European Journal of Public Health, vol 29, Issue 2, April, pages 351-358.

15. Katherine A, Linda L, Dahlberga $\mathrm{T}$, et al. (2015): Firearm injuries in the United States Prev Med. Official Journal Of The American Academy Of Pediatrics; October ; 79: 5-14.

16. Colorado Department of Public Health and Environment (CDPHE). (2014): 03JAN2014,firearm deaths in colorado 20052012.

17. Khan I, Shakeel M, Usmani JA, et al. (2016): Emerging Trends of Intentional Firearm Injuries in Northern India: A Study. J Clin. Diagn Res, Oct;10(10).

18. Shiffler T, Hargarten S, and Withers R. (2015): The burden of suicide and homicide of Wisconsin's children and youth. Wisconsin Medical journal; Volume (104).No.1.

19. Umaz M, Saad J, Sarah A, et al. (2018): Statistical Analysis of autopsy cases of homicides by firearm presented in forensic medicine department, Kemu, Lahore from January 2018 to December 2018 | A retrospective study, Pakistan postgraduate medical Jornal Vol. 29 No. 2 Apr. - Jun. (56$60)$.

20. Saleh SM. (2010): A preliminary study of firearm injury and death in Qena Governorate, Egypt in year 2008.Ain Shams J. Forensic Med. Clin. Toxicology; XIV:99-112.

21. Haider A, Jahanzeb $\mathrm{K}$ and Sohail $\mathrm{K}$. (2014): Demographic Distribution of Homicidal Firearm Injuries in Dera Ismail Khan. Gomal Journal of Medical Sciences; 12(1): $27-30$. 
22. Shah MM, Ali U, Fasseh-uz-Zaman, et al. (2008): Morbidity and mortality of firearm injury in Peshawar Region. J Ayub Med Coll Abbottabad;20:102-4.

23. Onuminya JE, and Ohwowhiagbese E. (2005): Pattern of civilian gunshot injuries in Irrua, Nigeria. S Afr J Surg; 43(4):170-2.

24. Papadopoulos I.N, Kanakaris N.K, Danias N, et al. (2013): Astructured autopsy-based audit of 370 firearm fatalities: Contribution to inform policy decisions and the probability of the injured arriving alive at a hospital and receiving definitive care. Accid Anal Prev; 50: 667-677.

25. Korai A, Khan S A, Iqbal P, et al. (2015): Spectrum of Firearm injuries in district Quetta. P J M H S; Vol. 9, NO. 3:900-902.

26. Al Madni O, Kharosha MA and Shotar AM. (2008): Firearm fatalities in Dammam, Saudi Arabia. Med Sci Law; Jul;48(3):237-40.

27. Kumar A, Sachan R and Verma A. (2015): Medico-Legal Evaluation of Firearm Injuries. $J$ Forensic Sci; 60(1).

28. Lasebikan A, Omoke I, Onyemaechi N, et al. (2020): prospective Analysis of Extremity Gunshot Injuries Treated in a Nigerian Regional Trauma Center, International Journal of Medicine and Health Development, Vol 24, Issue 2, February 10, IP: 10.232.74.23.
29. Sultana F Malik SA, Amir S et al. (2016): A Retrospective Study of Medico Legal Autopsies of Fire Arm injuries Deaths carried Out in Allama Iqbal Medical College Lahore during the Year 2014. Pakistan J. Medical and Health Sciences; V.10:756-760.

30. Edirisinghe PA and Kitulwatte IG. (2010): Homicidal firearm injuries: a study from Sri Lanka. Forensic Sci Med Pathol; 6(2):93-8.

31. Melissa M, Blessing DO, Peter $\mathrm{T}$, et al. (2016): Suicide by Shotgun in Southeastern Minnesota, J Forensic Sci; Vol. 61, No. S1.

32. Saad S, Salama M and Moghazy M. (2016): Incidence, topography, types of firearm injuries before and after the revolution of the 25th of January 2011: a hospital-based study. International Surgery Journal; 3(3): 11931198.

33. Sachan R, Kumar A and Verma A. (2013): Frequency of Firearm Injuries, Deaths and Related Factors in Kanpur, India. IJMTFM; 3(3): 88-95.

34. Fedakar R, Gundogmus UN and Turkmen N. (2007): Firearm-related deaths in two industrial cities of Turkey and their province. Leg Med (Tokyo); 9(1):14-21.

35. Hagras AM and Kharoshah MA. (2012): Medico-legal evaluation of firearm injuries during the period from 2005 to 2010 in the Suez Canal Area, Egypt:a retrospective study. Egypt J Forensic Sci; 2:1-10. 